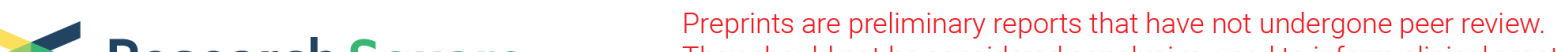 Research Square
or referenced not by the mediared conclusive, used to inform clinical practice,
onfed information.
}

\section{A description of the influenza vaccination program for health care workers in Vietnam}

Nga Ha ( $\sim$ ljv7@cdc.gov)

Centers for Disease Control and Prevention

Thoa Thi Minh Nguyen

US Centers for Disease Control and Prevention

\section{Tung Xuan Nguyen}

General Department of Preventive Medicine, Ministry of Health, Vietnam

Phu Dac Tran

General Department of Preventive Medicine, Ministry of Health, Vietnam

\section{Hang Minh Nguyen}

General Department of Preventive Medicine, Ministry of Health, Vietnam

\section{Van Thi Cam Ha}

General Department of Preventive Medicine, Ministry of Health, Vietnam

\section{Kathryn E. Lafond}

U.S. Center for Disease Control and Prevention

Jane F. Seward

Task Force for Global Health

Jeffrey W. McFarland

U.S. Centers for Disease Control and Prevention

Susan Y. Chu

U.S. Centers for Disease Control and Prevention

\section{Research article}

Keywords: influenza vaccine, health care workers, immunization.

Posted Date: April 27th, 2020

DOI: https://doi.org/10.21203/rs.3.rs-24293/v1

License: (9) This work is licensed under a Creative Commons Attribution 4.0 International License. Read Full License 
Version of Record: A version of this preprint was published on August 24th, 2020. See the published version at https://doi.org/10.1186/s12913-020-05663-y. 


\section{Abstract}

Background: In 2017, the Vietnam Ministry of Health conducted a demonstration project to introduce seasonal influenza vaccination to health care workers. A total of 11,000 doses of influenza vaccine, single-dose prefilled syringes, were provided free to HCWs at 29 selected hospitals, clinics, and research institutes in four provinces: Hanoi, Khanh Hoa, Dak Lak and Ho Chi Minh City.

Methods: Before the campaign, a workshop was organized to discuss an implementation plan including technical requirements, cold chain, uptake reporting, and surveillance for adverse events following immunization. All sites distributed communication materials and encouraged their staff to register for vaccination. Following immunization sessions, sites sent reports on uptake and adverse events following immunization. Left-over vaccine was transferred to other sites to maximize vaccine use.

Results: The average uptake was $57 \%$ for all health care workers, with 11 sites achieving $90 \%$ and above. These 11 sites were small with less than 500 staff, including 5 primary hospitals, 3 preventive medicine units, and 2 referral hospitals. Among the six biggest sites with over 1,000 staff, four sites had the lowest uptake (14\%-47\%). Most of the high-uptake sites were from the central to the south; only one site, a referral hospital, was from the north. After redistribution of left-over vaccine, only 130 vaccine doses $(1.2 \%)$ were not used and destroyed. Based on factors that affected uptake, including registration levels, differing communication strategies, availability of vaccination, and commitment by health facility leaders, we recommended ways to increase health care worker coverage; recommendations to improve reporting adverse events following immunization were also made.

Conclusions: The project demonstrated that it was feasible to conduct influenza vaccination campaigns among health care workers in Vietnam. Improvements in promotion of registration, more intense preplanning, especially at larger facilities, and wider, more consistent availability of communication materials will result in increased efficiency and coverage in this program's future expansion.

\section{Background}

Seasonal influenza vaccination can reduce morbidity and mortality from influenza disease and has been shown to be a safe, effective intervention in many, mostly developed countries [1, 2, 3]. In Vietnam, reported influenza-like illness affects 1.6 to 1.8 million persons per year and the country has experienced two major outbreaks of novel influenza viruses with pandemic potential, first in 2003 with highly pathogenic influenza A/H5N1 virus and in 2009 with influenza A/H1N1pdm09 virus [4]. As of July 2018, three trivalent influenza vaccines are licensed and imported into Vietnam, and include both Northern and Southern hemisphere formulations. Annually, about 700,000 doses are imported; even if all those doses are used, less than $1 \%$ of the population in Vietnam is vaccinated with influenza vaccine each year. [5].

In 2017, the Vietnam Ministry of Health $(\mathrm{MOH})$ conducted a demonstration project to introduce seasonal influenza vaccination among health care workers. 11,000 doses of vaccine were provided for health care workers (HCWs) at selected hospitals, clinics, and research institutes. HCWs are a priority group for 
influenza vaccination for several reasons. First, they may be at increased risk of contracting influenza at work. Second, influenza in this group may lead to nosocomial outbreaks, especially in immunocompromised patients. Third, available evidence suggests that influenza vaccination of HCWs may provide a protective effect for inpatients in health care settings $[6,7]$. Fourth, health care workers are key influencers and potential role models for influenza vaccine acceptance among other target groups [8, 9]. Last, health care workers are an accessible target population that can be reached through their employment sites. [10]

The Vietnam $\mathrm{MOH}$ recognized the higher risk of influenza infection in this target group in the 2011 guidelines for seasonal influenza diagnosis and treatment, and recommended them as a target group for annual influenza vaccination in the 2013 plan on production and use of influenza vaccine [11, 12]. However, this demonstration project is the first major effort to implement this recommendation and increase vaccine uptake in this important group. This paper describes the process and results of this effort, including key findings and recommendations for further expansion of influenza vaccination in Vietnam.

\section{Methods}

\section{Project timeline and selection of health facilities}

This paper aims to describe the process and results of the influenza immunization campaign for health care workers, and highlight key findings and recommendations for further expansion of influenza vaccination in Vietnam. The immunization campaign was conducted from January to May 2017 in selected health units. Criteria for selecting these sites were that the health facilities (i) were willing and supportive of influenza vaccination; (ii) were representative of the region; and (iii) had staff committed to implementing the project. In this demonstration project, health care workers were defined as all medical and non-medical staff of health facilities including permanent and contract personnel. Immunization is on voluntary basis for health units as well as health care workers.

According to the original plan, ten hospitals and preventive medicine centers were selected in four cities/provinces, one in each of the four medical regions, North, Central, Central Highlands and South. They are listed below:

- National Hospital for Tropical Diseases (Hanoi),

- Bach Mai Hospital (Hanoi),

- National Hospital for Obstetrics and Gynecology (Hanoi),

- National Institute of Hygiene and Epidemiology (Hanoi),

- Khanh Hoa General Hospital (Khanh Hoa)

- Dak Lak General Hospital (Dak Lak),

- Cho Ray Hospital (Ho Chi Minh City), 
- Tu Du Hospital (Ho Chi Minh City),

- Hospital for Tropical Diseases of HCM City (Ho Chi Minh City),

- Pasteur Institute - HCM City (Ho Chi Minh City)

Of the ten sites, four sites had certified trained immunizers; these staff conducted the influenza immunization sessions at both their own facilities and the other six sites.

\section{Preparatory activities}

In preparation for the campaign, a workshop on planning for the immunization program was conducted with all participating sites to discuss the implementation plan, logistic preparations, and administrative and technical requirements in the campaign. A critical activity for preparation was determining how many health care workers were at each health facility were willing to get immunization, who were required to sign up in a registration list. Most of the sites announced the vaccination campaign through briefings, posted the information on the facility's staff website, and/or sent notifications and registration forms by email or hard copy to all departments. At each site, a focal person was assigned to collect and consolidate lists of registered health care workers from all departments. Upon having the full registration list, sites informed $\mathrm{MOH}$ of the quantity of vaccines they needed.

\section{Vaccines}

Vaccine for this project, funded by the Cooperative Agreement IP000821 between U.S. CDC and the General Department of Preventive Medicine (GDPM), was Influvac, single-dose pre-filled syringe influenza vaccine manufactured by Abbott Biologicals B.V., Netherlands containing the northern hemisphere 16/17 formulation with an expiry date of June 30,2017 . [13]

\section{Vaccine transportation and storage plan}

$\mathrm{MOH}$ had Phuc Thien Pharmaceutical Joint Stock Company distribute the 11,000 vaccine doses to the sites. The cold chain was maintained with temperature checks during storage, delivery, and receipt, which were documented. The cold chain system of the National Extended Program for Immunization was in place at two sites; other sites used their own cold chain system.

On a vaccination session day, vaccines were transported from cold storage to immunization sites in standardized cold boxes as per regulations. Unused vaccine at the end of the session was returned to cold storage. After each site completed their vaccinations, the vaccination team made a final record of vaccine used and any unused doses were later reallocated to other sites. The reallocation prioritized sites in the same province to minimize transportation costs. It was reported by all sites that the storage of influenza vaccines for this demonstration project did not cause any changes or impacts to the storage plan of other vaccines or the overall plan of the existing cold chain systems.

\section{Immunization sessions}


Vaccination teams were set up to carry out immunization; each team included one officer to list vaccine recipients and distribute vaccination certificates after immunization, one physician to screen participants, and one vaccinator. Smaller sites used one team, the largest sites used three teams, but most commonly, two teams were established for the immunization sessions. To avoid overcrowding, different departments came for immunization at different times. All sites reported that the arrangement for the campaign did not significantly affect their routine professional work.

\section{Reporting and monitoring of immunization}

All immunization sites were required to send a daily summary after each vaccination session and a final report by the end of the immunization campaign. The daily summary included a list of the day's vaccine recipients and any AEFI cases with appropriate details. AEFIs were monitored for 30 minutes at the immunization site or were reported to the immunization hotline within 24 hours after vaccinations, with daily summaries compiled into an all-site database. These requirements are in consistent with Ministry of Health's reporting requirements for routine immunization activities.

To ensure the timeliness and quality of reporting, each site assigned one person to consolidate daily the list of vaccine recipients, and coordinate the number of vaccines needed, used and remaining. If the number of health care workers vaccinated was lower than expected, reminders were sent out to registered $\mathrm{HCWs}$; and the site also made extra efforts to encourage HCWs to come for vaccination. This helped the site to reach as many registered HCWs as possible, and even reached HCWs who had not registered for vaccination. The timeliness of daily summaries and final reports from sites to $\mathrm{MOH}$ made transfer of leftover vaccines to other sites possible, greatly reducing vaccine wastage.

$\mathrm{MOH}$ sent staff to all sites to provide technical support and monitor activities. U.S.CDC joined $\mathrm{MOH}$ to monitor at some immunization sites. The monitoring and technical oversight helped identify drawbacks and implement timely adjustments.

\section{Communication campaign}

At each site, registered HCWs were provided a written summary about influenza and influenza vaccine. Some site leaders organized all-hands meetings where they advocated for the influenza vaccination campaign, highlighted the importance of vaccine and encouraged staff to get immunized. During the vaccination session, vaccination staff advised HCWs on the benefits of influenza vaccine and its possible side effects. After getting the shot, each health care worker got a certificate of immunization (each site designed its own certificate). However, because all communication materials developed by $\mathrm{MOH}$ for this campaign were not completed before the vaccination started, most sites noted a lack of adequate communication materials, resulting in some HCWs not understanding the purpose of the vaccination campaign and the benefits of influenza immunization, and not registering or coming for vaccination.

\section{Results}


Ten sites were selected at the beginning of the project. However, during implementation, some large sites, such as Bach Mai and Cho Ray Hospitals, had a lower than expected number of health care workers register for vaccination. This resulted in a considerable number of left-over vaccine doses. For this reason, an additional 19 sites in the same four provinces/cities were added to utilize the remaining vaccine. Criteria for selection of additional sites were that the health facilities (i) must be located in the four selected provinces, and (ii) were willing to be part of this demonstration project.

The additional 19 sites are listed below:

- 1 site in Hanoi: General Department of Preventive Medicine (GDPM)

- 1 site in Ho Chi Minh City: Hung Vuong Hospital, Preventive Medicine Center

- 10 sites in Khanh Hoa: Khanh Hoa Hospital of Tropical Diseases, Khanh Hoa Preventive Medicine Center, Pasteur Institute - Nha Trang, Khanh Hoa Health Department, Ninh Hoa District General Hospital, Cam Ranh General Hospital, Hospital of Tuberculosis and Lung Diseases in Khanh Hoa, Health Center of Nha Trang City, Van Ninh District Health Center,

- 7 sites in Dak Lak: Dak Lak Preventive Medicine Center, General Hospital Thien Hanh, General Hospital of Buon Ma Thuot City, Buon Ma Thuot Health Center, General Hospital of Buon Ho district, Buon Ho Health Center, and Tay Nguyen Institute of Hygiene and Epidemiology

Thus, the vaccination campaign was eventually conducted in 29 sites in four provinces.

\section{Vaccine used}

Average uptake of this vaccination program was $57 \%$ of all HCWs, with 11 sites achieving $90 \%$ and above. These 11 sites were small with less than 500 staff, which included 5 primary hospitals, 3 preventive medicine units, and 2 referral hospitals. Most of them were from the central to the south; only one site was from the north, this was a referral hospital. Among the six biggest sites with over 1,000 staff, four sites had the lowest uptake, from $14 \%$ to $47 \%$.

Among those HCWs who registered, the average proportion of vaccine recipients were $87 \%$, which was relatively high. At some sites, the number of vaccinated staff exceeded the number of registered staff, reflecting the availability of doses for all HCWs wanting to be vaccinated.

In Hanoi, leftover vaccines were allocated to GDPM in Hanoi and other sites in Dak Lak and Khanh Hoa provinces. Left-over vaccines in Ho Chi Minh City, Dak Lak and Khanh Hoa were transferred to other sites in the same province. The vaccine storage, transportation and delivery were done strictly according to regulations. Only 130 (1.2\%) of 11,000 vaccine doses were not used before the expiry date; these 130 doses were destroyed.

\section{Adverse events following immunization}


Vaccination sites had trained staff and necessary equipment and medicines to treat acute severe AEFIs immediately and appropriately. However, most HCWs would not stay at the vaccination site for the full 30 minutes, with some saying they could monitor themselves and return if anything went wrong. There were $38 \mathrm{AEFI}$ cases reported from 7 sites, including pain at the injection site, mild fever, cough, or dizziness. All reported AEFIs were mild and resolved in a few days. There were no severe AEFI cases.

\section{Discussion}

This demonstration project showed that an influenza immunization program among health care workers in Vietnam was feasible, acceptable, and could attain good coverage.

One key finding was the very low wastage rate of vaccines. The use of single dose prefilled syringes in this demonstration project helped ensure lower wastage than is typical of other vaccine presentations, particularly multi-dose vaccine vials (15). In addition, timely redistribution of unused vaccine to additional health facilities further reduced wastage. However, frequent redistribution of vaccine doses is not ideal for future program planning, and the key findings from this demonstration project in projecting site-level uptake can inform improvements in Vietnam's influenza immunization program for health care workers.

The key findings were:

1. Registration by HCWs in most sites improved vaccination coverage. This was a more important factor in the larger sites, as the six largest sites each with more than 1,000 staff had lower registration rates $(54 \%)$ than the rate for all remaining sites (86\%).

2. Sites where leaders actively advocated for influenza immunization and strongly encouraged their staff to get vaccinated had higher uptake of vaccine.

3. Overall coverage was lower among health facilities with larger staff ( $>500 \mathrm{HCWs}$ ). In addition to the lower registration rates in larger facilities, wide distribution of communication materials was more challenging and there were fewer opportunities for face-to-face advocacy efforts. This also could be related to increased workloads at larger sites, making vaccination sessions more difficult for HCWs to prioritize and attend. The exceptions to this finding were the two tropical diseases hospitals, (which specialize in infectious diseases), that had better uptake, perhaps due to greater awareness of their occupational exposure to influenza.

4. It is possible that that AEFIs, especially mild reactions, were underreported. Many HCWs did not stay for the entire 30 minute post vaccination monitoring time. Only seven of 29 sites reported any AEFIs and only one site, Ho Chi Minh City Hospital of Tropical Diseases reported more than 2 AEFIs. No serious AEFIs were reported, but because the program was conducted among HCWs in hospitals or clinics, it is unlikely serious AEFIs were missed.

5. The storage of vaccines for this demonstration project did not affect the storage plan of other vaccines or the overall plan of the existing cold chain systems, given that the quantity of vaccine in the project were not a significantly large number. 
Based on these findings, several key recommendations were made to improve coverage and efficiency of the immunization program for HCWs in Vietnam.

Key recommendations include:

1. Greater promotion of the registration process and closer timing of the registration process to the vaccination session dates. A system should be developed for reminding $\mathrm{HCWs}$, both registered and unregistered, of the dates and times of the vaccination sessions.

2. Obtain hospital leaders strong active commitment to the immunization activity.

3. Earlier and more intense planning at larger sites and specialized health facilities. Management should ensure that HCWs have the time and opportunity to attend vaccination sessions, especially in more work-intensive settings.

4. Communication materials should be improved, including more emphasis of the increased risks of exposure and benefits of protection to the HCWs, their families, and their patients. These materials should be made available well in advance and during registration and vaccination sessions.

5. Ensure that HCWs are aware of AEFls, emphasizing the extreme rarity of serious reactions while also stressing the importance for AEFI surveillance.

6. For a more extensive immunization program in the future, it's critical to examine if the existing cold chain is capable to store an extra amount of vaccines. The expansion of the cold chain should be considered, if needed, to ensure vaccine be stored in qualified conditions.

\section{Conclusion}

The project demonstrated that it was acceptable to conduct influenza vaccination campaigns among HCWs in Vietnam. Expansion of this program to more HCWs at more sites is likely achievable. Key findings and recommendations from this project could help improve coverage and efficiency of delivery in future influenza immunization efforts in HCWs.

\section{List Of Abbreviations}

AEFI: $\quad$ Adverse event following immunization

GDPM: $\quad$ General Department of Preventive Medicine

HCW: $\quad$ Healthcare worker

$\mathrm{MOH}: \quad$ Ministry of Health

U.S. CDC: Centers for Diseases Control and Prevention. 


\section{Declarations}

Ethics approval and consent to participate: not applicable. The immunization campaign, organized by Ministry of Health, strictly followed Government of Vietnam's policy on routine immunization namely Decree 104/2016/NĐ-CP issued by the Government of Vietnam on July 1 st, 2016 . By signing up for the registration list of immunization, all health units and healthcare workers voluntarily participated in the campaign; thus no consent form was required. Since this was a routine activity, ethic committee was not established.

Consent for publication: not applicable.

Availability of data and materials: All data generated or analysed during this study are included in this published article.

\section{Competing interests:}

The authors declare that they have no competing interests.

\section{Funding:}

Financial funding for this vaccination program came from the U.S. CDC via Influenza Division's cooperative agreement with GDPM, IP000821. U.S. CDC provides financial funding as well as technical assistance including the design of the study, dataanalysis and interpretation and writing of the manuscript.

\section{Authors' contributions:}

N.H developed conceptualization, methodology, analysed data, wrote, reviewed and edited the manuscript. T.T.M.N. involved in conceptualization, methodology, data analysis, review and editing of the paper. T.X.N. conducted investigation, provided supervision to the immunization project and reviewed the paper. P.T. conducted investigation, provided supervision to the immunization project and reviewed the paper. H.N. conducted investigation, provided supervision to the immunization project and reviewed the paper. V.H. contributed to the conceptualization, methodology of the paper, participated in investigation, project administration and supervision of the project and reviewed the paper. K.L. made contribution to the conceptualization, methodology, data analysis, review and editing of the paper. J.S. made contribution to the conceptualization, methodology, data analysis, writing, review and editing of the manuscript. J.M. contributed to the conceptualization, methodology, data analysis, writing, review and editing of the paper. S.C. involved in to the conceptualization, methodology, data analysis, writing, review and editing of the paper. All authors read and approved the final manuscript.

\section{Acknowledgements:}

We would like to thank colleagues from GDPM(MOH) for their coordination and contribution during the vaccination campaign. Our thanks also goes to 29 implementing health facilities and all health care 
workers who participated in the campaign. We acknowledge valuable support by colleagues who reviewed the paper.

\section{Disclaimer:}

The findings and conclusions in this report are those of the authors and do not necessarily represent the official position of the Centers for Disease Control and Prevention.

\section{References}

1. Breteler JK, Tam JS, Jit M, Ket JC, De Boer MR. Efficacy and effectiveness of seasonal and pandemic A (H1N1) 2009 influenza vaccines in low and middle income countries: a systematic review and meta-analysis. Vaccine. 2013;31(45):5168-77.

2. Andrew MK, Shinde V, Hatchette T, Ambrose A, Boivin G, Bowie W, et al. Influenza vaccine effectiveness against influenza-related hospitalization during a season with mixed outbreaks of four influenza viruses: a test-negative case-control study in adults in Canada. BMC Infect Dis. 2017; 17(1):805

3. World Health Organization. 2017 [2018 january 1]. Vaccine use http://www.who.int/influenza/vaccines/use/en/. Accessed 16 December 2019.

4. Vietnam Ministry of Health. Health Statistics yearbook 2015. 2017

5. World Health Organization. Made in Viet Nam vaccines: efforts to develop sustainable in-country manufacturing for seasonal and pandemic influenza vaccines: consultation held in Vietnam, April June 2016. 2017

6. Pavia AT. Mandate to protect patients from health care-associated influenza. Clinical Infect Dis. 2010; 50:465-7.

7. Poland GA, Tosh P, Jacobson RM. Requiring influenza vaccination for health care workers: seven truths we must accept. Vaccine. 2005; 23:2251-5.

8. Ditsungnoen D, Greenbaum A,Praphasiri P, Dawood FS, Thompson MG, Yoocharoen P et al. Knowledge, attitudes and beliefs related to seasonal influenza vaccine among pregnant women in Thailand. 2016 Apr 19;34 (18): 2141-6

9. Ying Song, Tao Zhang, Liling Chen, Bo Yi, Xiaoning Hao, Suizan Zhou et al. Increasing seasonal influenza vaccination among high risk groups in China: Do community healthcare workers have a role to play? Vaccine. 2017. 35: 4060-4063

10. Advisory Committee on Immunization P, Centers for Disease C, Prevention. Immunization of healthcare personnel: recommendations of the Advisory Committee on Immunization Practices (ACIP). MMWR Recomm Rep. 2011;60(RR-7):1-45.

11. Vietnam Ministry of Health. Decision No.2078/QĐ-BYT dated 23/6/2011 of Minister of Health regarding Guidelines of Seasonal influenza diagnose and treatment. 
12. Vietnam Ministry of Health. Decision No.1950/QĐ-BYT dated 6/6/2013 of Minister of Health regarding Plan for development and use of influenza vaccines.

13. Influvac® 2016/2017 package insert. http://mri.cts-mrp.eu/download/NL_H_0137_001_FinalPL.pdf.

14. Vietnam Ministry of Health. Decision No.1731/QĐ-BYT dated 3/5/2017 by Minister of Health guiding the arrangement of an immunization session.

15. Drain PK, Nelson CM, Lloyd JS. Single-dose versus multi-dose vaccine vials for immunization programmes in developing countries. Bull World Health Organ. 2003;81(10):726-31

\section{Tables}

Table 1: Coverage of influenza vaccination at 29 sites, 2017 demonstration project, Vietnam 


\begin{tabular}{|c|c|c|c|c|c|c|}
\hline o. & Name of sites & $\begin{array}{l}\text { Number } \\
\text { of staff }\end{array}$ & $\begin{array}{c}\text { Number of } \\
\text { registered } \\
\text { people }\end{array}$ & $\begin{array}{l}\text { Number of } \\
\text { immunized } \\
\text { people }\end{array}$ & $\begin{array}{c}\text { \% immunized } \\
\text { per } \\
\text { registered }\end{array}$ & $\begin{array}{l}\text { Uptake rate (\% } \\
\text { immunized per all } \\
\text { staff) }\end{array}$ \\
\hline L & $\begin{array}{l}\text { Buon Ho District Health } \\
\text { Center }\end{array}$ & 75 & 50 & 75 & $150 \%$ & $100 \%$ \\
\hline 2 & $\begin{array}{l}\text { Ho Chi Minh City Provincial } \\
\text { Preventive Medicine Center }\end{array}$ & 170 & 167 & 170 & $102 \%$ & $100 \%$ \\
\hline 3 & $\begin{array}{l}\text { Pasteur Institute of Nha } \\
\text { Trang }\end{array}$ & 170 & 169 & 170 & $101 \%$ & $100 \%$ \\
\hline 1 & $\begin{array}{l}\text { Khanh Hoa Provincial } \\
\text { Preventive Medicine Center }\end{array}$ & 60 & 60 & 60 & $100 \%$ & $100 \%$ \\
\hline j & $\begin{array}{l}\text { Khanh Hoa Hospital of } \\
\text { Tropical Diseases }\end{array}$ & 130 & 130 & 130 & $100 \%$ & $100 \%$ \\
\hline j & $\begin{array}{l}\text { Van Ninh District Health } \\
\text { Center }\end{array}$ & 164 & 164 & 164 & $100 \%$ & $100 \%$ \\
\hline 7 & $\begin{array}{l}\text { Buon Ma Thuot City Health } \\
\text { Center }\end{array}$ & 50 & 50 & 50 & $100 \%$ & $100 \%$ \\
\hline 3 & $\begin{array}{l}\text { Pasteur Institute of Ho Chi } \\
\text { Minh City }\end{array}$ & 370 & 370 & 370 & $100 \%$ & $100 \%$ \\
\hline 3 & $\begin{array}{l}\text { Buon Ho District General } \\
\text { Hospital }\end{array}$ & 300 & 300 & 295 & $98 \%$ & $98 \%$ \\
\hline 0 & $\begin{array}{l}\text { National Hospital of Tropical } \\
\text { Diseases }\end{array}$ & 480 & 470 & 455 & $97 \%$ & $95 \%$ \\
\hline 1 & $\begin{array}{l}\text { Dak Lak Provincial } \\
\text { Preventive Medicine Center }\end{array}$ & 67 & 60 & 60 & $100 \%$ & $90 \%$ \\
\hline 2 & $\begin{array}{l}\text { General Department of } \\
\text { Preventive Medicine }\end{array}$ & 79 & 70 & 70 & $100 \%$ & $89 \%$ \\
\hline 3 & Dak Lak General Hospital & 1,264 & 1,186 & 1,095 & $92 \%$ & $87 \%$ \\
\hline 4 & Khanh Hoa General Hospital & 1,400 & 1,203 & 1,205 & $100 \%$ & $86 \%$ \\
\hline 5 & $\begin{array}{l}\text { Tay Nguyen Institute of } \\
\text { Hygiene and Epidemiology }\end{array}$ & 138 & 114 & 116 & $102 \%$ & $84 \%$ \\
\hline
\end{tabular}




\begin{tabular}{|c|c|c|c|c|c|c|}
\hline o. & Name of sites & $\begin{array}{l}\text { Number } \\
\text { of staff }\end{array}$ & $\begin{array}{l}\text { Number of } \\
\text { registered } \\
\text { people }\end{array}$ & $\begin{array}{l}\text { Number of } \\
\text { immunized } \\
\text { people }\end{array}$ & $\begin{array}{c}\text { \% immunized } \\
\text { per } \\
\text { registered }\end{array}$ & $\begin{array}{l}\text { Uptake rate (\% } \\
\text { immunized per all } \\
\text { staff) }\end{array}$ \\
\hline 6 & $\begin{array}{l}\text { Buon Ma Thuot City General } \\
\text { Hospital }\end{array}$ & 300 & 300 & 252 & $84 \%$ & $84 \%$ \\
\hline 7 & $\begin{array}{l}\text { Khanh Hoa Department of } \\
\text { Health }\end{array}$ & 60 & 60 & 50 & $83 \%$ & $83 \%$ \\
\hline 8 & Hung Vuong Hospital & 750 & 750 & 620 & $83 \%$ & $83 \%$ \\
\hline 9 & Thien Hanh Hospital & 500 & 500 & 395 & $79 \%$ & $79 \%$ \\
\hline 0 & $\begin{array}{l}\text { Nha Trang City Health } \\
\text { Center }\end{array}$ & 430 & 300 & 334 & $111 \%$ & $78 \%$ \\
\hline 1 & $\begin{array}{l}\text { Ninh Hoa Regional General } \\
\text { Hospital }\end{array}$ & 291 & 300 & 214 & $71 \%$ & $74 \%$ \\
\hline 2 & $\begin{array}{l}\text { National Institute of } \\
\text { Hygiene and Epidemiology }\end{array}$ & 337 & 262 & 240 & $92 \%$ & $71 \%$ \\
\hline 3 & $\begin{array}{l}\text { Ho Chi Minh City Hospital of } \\
\text { Tropical Diseases }\end{array}$ & 690 & 521 & 475 & $91 \%$ & $69 \%$ \\
\hline 4 & $\begin{array}{l}\text { Cam Ranh Regional General } \\
\text { Hospital }\end{array}$ & 300 & 300 & 173 & $58 \%$ & $58 \%$ \\
\hline 5 & Tu Du Hospital & 2,500 & 1,185 & 1,185 & $100 \%$ & $47 \%$ \\
\hline 6 & $\begin{array}{l}\text { Khanh Hoa Hospital of Lung } \\
\text { and Tuberculosis Diseases }\end{array}$ & 100 & 100 & 38 & $38 \%$ & $38 \%$ \\
\hline 7 & Bach Mai Hospital & 2,790 & 1,500 & 1,043 & $70 \%$ & $37 \%$ \\
\hline 8 & Cho Ray Hospital & 3,800 & 1,560 & 1,199 & $77 \%$ & $32 \%$ \\
\hline \multirow[t]{2}{*}{9} & $\begin{array}{l}\text { National Hospital of } \\
\text { Obstetrics and Gynecology }\end{array}$ & 1,170 & 350 & 167 & $48 \%$ & $14 \%$ \\
\hline & TOTAL & 18,906 & 12,551 & 10,870 & $87 \%$ & $57 \%$ \\
\hline
\end{tabular}

Table 2: Adverse events following influenza vaccination at the 2017 demonstration project. 


\begin{tabular}{|c|l|c|c|}
\hline No. & Name of sites & $\begin{array}{c}\text { No. of immunized } \\
\text { people }\end{array}$ & No. of AEFI cases \\
\hline 1 & $\begin{array}{l}\text { Gynocology } \\
\text { Kanal Hospital of Obstetric and }\end{array}$ & 167 & 1 mild case \\
\hline 2 & Khanh Hoa General Hospital & 1,205 & 1 mild case \\
\hline 3 & Regional General Hospital of Cam Ranh & 173 & 1 mild case \\
\hline 4 & Dak Lak General Hospital & 1,095 & 2 mild cases \\
\hline 5 & Buon Ho District Health Clinic & 75 & 30 mild cases: sore at injection \\
\hline 6 & Ho Chi Minh City Hospital of Tropical & 475 & site \\
\hline 7 & Cho Ray Hospital & 1,199 & 2 mild cases \\
\hline
\end{tabular}

